\title{
Implementation of Decision Support System for Determination of Employee Contract Extension Method Using SAW
}

\author{
Baik Sepwanri Sinaga $^{1}$, Fristi Riandari ${ }^{2}$ \\ ${ }^{1.2}$ Teknnik Study Program Informatics, STMIK Pelita Nusantara, J1. Iskandar Muda No. 1 \\ Medan, North Sumatra, Indonesia 20154
}

E-mail: baiksinaga2015@gmail.com

\begin{abstract}
Effect of rapid technological developments have contributed so as to provide an opportunity to study and analyze a problem. In the company of PT. Cipta Mandiri Agung Jaya, employee contract renewal process is done in less efficient. In general, the process of employee contract extension is carried out by way of division form a contract extension, has not made an assessment atupun evaluation of each employee. Through employee contract renewal process conducted so far gives a great influence to the advancement of the company. On this occasion, in view of the managerial aspects of the formulation of the problem is how to implement the SAW method in the determination of employee contract extension. How to implement a decision support system in the determination of contract extensions employees at PT. Court Of Human Self Jaya, how to design decision support systems in the SAW method using the employee contract extension programming language VB 2010 and the Microsoft Access database. The purpose was to analyze the issue formulation SAW method in the determination of employee contract extension, implementing a decision support system in the determination of contract extensions employees at PT. Court Of Human Self Jaya, pendukunng system design decisions in the SAW method using the employee contract extension programming language VB 2010 and the Microsoft Access database.
\end{abstract}

Keywords: Decision Support Openness, SAW Method

\section{Introduction}

Employees greatly affect many aspects of determining the success of a company where employees serve as a spearhead in running the company. To that extend the contract employee takes an appropriate decision in order to maintain the stability of the company. Currently karyawaan contract extension processing is less efficient and have not conducted an evaluation to every employee so as to give effect to the progress of the company. With the research gives the chance to lift a method used to determine the employee's contract extension is the method of Simple Additive Weight (SAW) where this method gives the criteria or the scale of values that serve as the decision. The shelter of data is by using the Microsoft Access database and programming language Visual Basic 2010. The purpose of the study is 1) How to implement SAW method in the determination of contract extensions karyawan.2) Implement a decision support system in the determination of contract extensions employees at PT. COPYRIGHT MANDIRI JAYA AGUNG. 3) Designing a system pendukunng SAW method decision in the employee contract extension using VB programming language and database microsoft access 2010

\section{Theory}

\section{A. System}

The system is a collection of interrelated elements that are responsible to process inputs (inputs) to produce output. In making this system takes various fererensi or journals that can help the process of making this system. Stage of development of this system are: 1) Intelligence is a process of search and detection of the scope of the problems in the process of recognition of the problem, the data input obtained from order to identify the problem. 2) Design is a process of discovering, developing and analyzing alternative actions that can be performed dengann melakukukan sousi feasibility test. 3) Choice selection stage is an alternative actions that might be used as a reference, the results are used in the process of system development decisions. Decision system is the result of the process of choosing the best option among the alternatives field is available which assisted with a method in decision-making. Simple Additive Weighting (SAW) is one method of multi-criteria decision making are simple and classic. This method is included in the weighting method otherwise known as a weighted summation method. The basic concept of SAW is looking for a weighted summation of the 
performance of each alternative on all attributes, requires a process of normalizing the decision matrix (X) to a scale that can be compared with all the ratings alternatives ada.Adapun completion step in this method is Simple Additive Weighting (SAW) is one method of multi-criteria decision making are simple and classic. This method is included in the weighting method otherwise known as a weighted summation method. The basic concept of SAW is looking for a weighted summation of the performance of each alternative on all attributes, requires a process of normalizing the decision matrix $(\mathrm{X})$ to a scale that can be compared with all the ratings alternatives ada.Adapun completion step in this method is Simple Additive Weighting (SAW) is one method of multicriteria decision making are simple and classic. This method is included in the weighting method otherwise known as a weighted summation method. The basic concept of SAW is looking for a weighted summation of the performance of each alternative on all attributes, requires a process of normalizing the decision matrix (X) to a scale that can be compared with all the ratings alternatives ada.Adapun completion step in this method is

$$
\left\{\begin{array}{c}
\frac{x_{i j}}{M_{i} a x x i j} \text { If } \mathrm{J} \text { is an attribute } \\
\text { if } \mathrm{j} \text { is to make the cost (cost) } \frac{M_{i} i n x_{i j}}{\mathrm{x}_{\mathrm{ij}}}
\end{array}\right.
$$

Where :

Rij = Rating normalized performance

Maxij $=$ The maximum value of each row and column

Minij = minimum value of each row and column

$\mathrm{Xij}=$ rows and columns of a matrix

With Rij is normalized performance rating of alternatives on attribute $\mathrm{Ai} \mathrm{Cj} ; \mathrm{i}=1,2, \ldots \mathrm{m}$ and $\mathrm{j}=1,2, \ldots, \mathrm{n}$.

$$
\mathrm{V}_{\mathrm{i}}=\mathrm{R}_{\mathrm{ij}}
$$

Vi larger value indicates that the alternative Ai is selected.

Where :

$\mathrm{Vi}=$ The final value of the alternative

$\mathrm{Wi}=$ Weight predetermined

Rij $=$ Normalization matrix

There are several steps in the completion of the method Simple Additive Weight (SAW) is as follows:

a) Specify the criteria used as a reference in decision support that is $\mathrm{Ci}$.

b) The rating determines the suitability of each alternative on each criterion.

c) Make decisions based on criteria matrix (Ci).

d) Then normalizing matrix based on equations that are tailored to the type of attributes (attributes and attribute benefit costs) in order to obtain the normalized matrix R.

The final result is obtained from the process of ranking the sum of the normalized $\mathrm{R}$ matrix multiplication with a weight vector to obtain value. Here's the translation of research results of the determination of employee contract extension using Simple Additive Weight (SAW).

\section{Research methods}

\section{A. Framework Research}




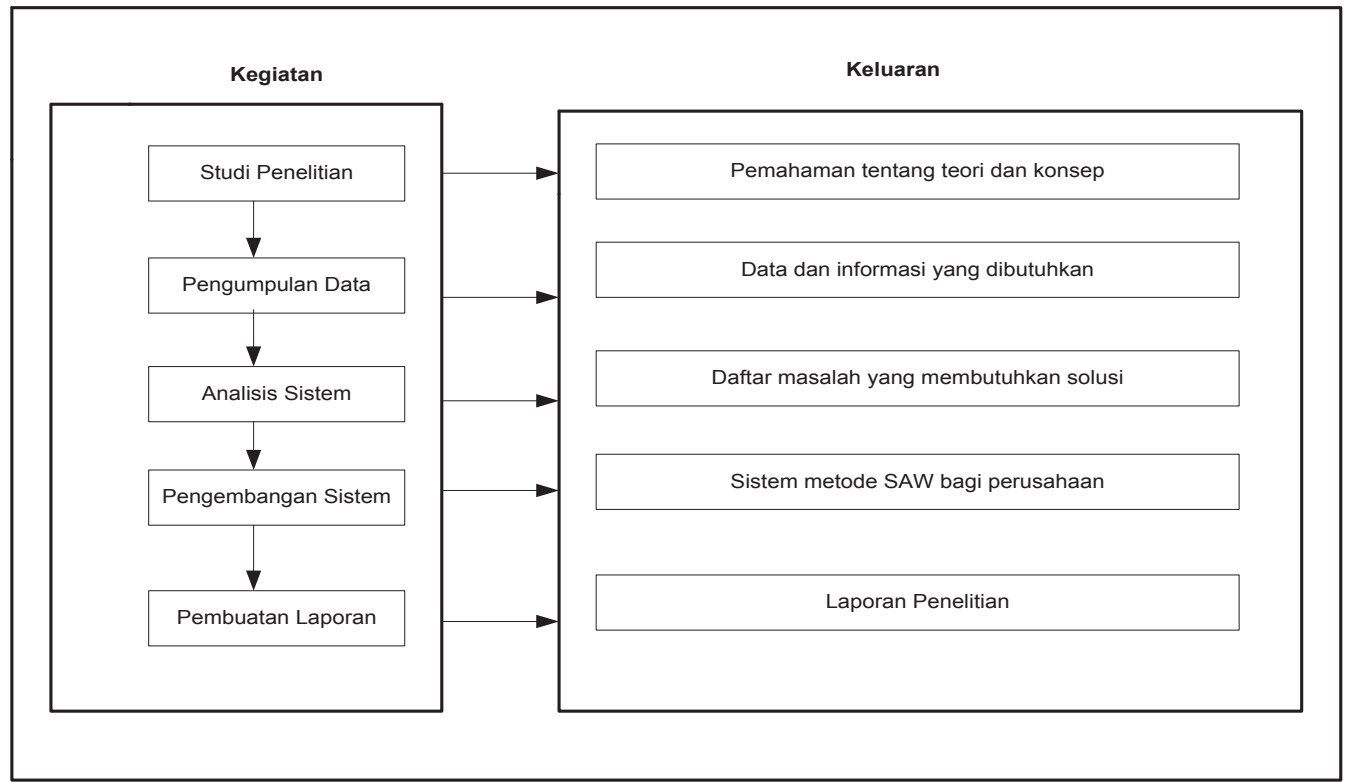

Fig 1. Research Framework

4. Analysis

Table 1.

weights Criteria

\begin{tabular}{ccccccc}
\hline & \multicolumn{7}{c}{ weights Criteria } \\
\cline { 2 - 7 } Alternative & C1 & C2 & C3 & C4 & C5 & C6 \\
\hline A1 & 1 & 0.8 & 0.8 & 1 & 1 & 0.8 \\
A2 & 0.8 & 0.6 & 0.8 & 0.8 & 0.8 & 0.6 \\
A3 & 0.6 & 0.6 & 0.6 & 0.8 & 0.6 & 0.6 \\
A4 & 1 & 0.6 & 0.6 & 1 & 1 & 0.8 \\
A5 & 1 & 0.8 & 0.8 & 0.6 & 1 & 0.8 \\
\hline
\end{tabular}

$\mathrm{R}=\left[\begin{array}{lllllll}1 & 0.8 & 0.8 & 1 & 1 & 0.8 \\ 0.8 & 0.6 & 0.8 & 0.8 & 0.8 & 0.6 \\ 0.6 & 0.6 & 0.6 & 0.8 & 0.6 & 0.6 \\ 1 & 0.6 & 0.6 & 1 & 1 & 0.8 \\ 1 & 0.8 & 0.8 & 0.6 & 1 & 0.8\end{array}\right]$

a) Work Discipline Criteria (benefit)

$$
\begin{aligned}
& \mathrm{R} 1.1=\frac{1}{\operatorname{Max} 1 ; 0,8 ; 0,6 ; 1 ; 1}=\frac{1}{1}=1 \\
& \mathrm{R} 2.1=\frac{0,8}{\operatorname{Max} 1 ; 0,8 ; 0,6 ; 1 ; 1}=\frac{0,8}{1}=0,8 \\
& \mathrm{R} 3.1=\frac{0,6}{\operatorname{Max} 1 ; 0,8 ; 0,6 ; 1 ; 1}=\frac{0,6}{1}=0,6 \\
& \mathrm{R} 4.1=\frac{1}{\operatorname{Max} 1 ; 0,8 ; 0,6 ; 1 ; 1}=\frac{1}{1}=1 \\
& \mathrm{R} 5.1=\frac{1}{\operatorname{Max} 1 ; 0,8 ; 0,6 ; 1 ; 1}=\frac{1}{1}=1
\end{aligned}
$$

